\title{
Current surgical training: simultaneous training in open and laparoscopic surgery
}

\author{
Nobuyasu Kano • Akihiko Takeshi $\cdot$ Hiroshi Kusanagi $\cdot$ Yu Watarai · \\ Makio Mike · Shigetoshi Yamada $\cdot$ Osamu Mishima $\cdot$ Seiko Uwafuji • \\ Michiko Kitagawa $\cdot$ Hiroyuki Watanabe $\cdot$ Seiichi Kitahama $\cdot$ Satoshi Matsuda \\ Satoshi Endo • David Gremillion
}

Published online: 29 July 2010

(C) The Author(s) 2010. This article is published with open access at Springerlink.com

Endoscopic surgery has been widely accepted in various surgical fields, and for some surgeries such as cholecystectomy, these procedures are performed primarily by laparoscopic technique [1]. Consequently, concerns about education for open surgery have appeared, with some educators cautioning that "if so many surgeries are done using laparoscopy, chances for open conventional surgery critically decreases."

At the early stage of laparoscopic surgery, the prime concern was how to train experienced surgeons to be eligible for laparoscopic surgery [2]. Kimura and Suzuki [3] described training for laparoscopy as follows: The experienced and competent surgeons must learn anatomy specific to laparoscopic surgery for each organ, tactical sensation and hand-eye coordination under a two-dimensional monitor, and knowledge of instruments specific to laparoscopic surgery. Scott et al. reported that $67 \%$ of biliary injury in laparoscopic cholecystectomy (LC) was encountered during the first 25 cases of each surgeon's experience [4]. According to the Southern Surgical Club, the incidence of biliary injury during LC in all member institutions of the club was $2.2 \%$, although this included only $0.1 \%$ of the

\footnotetext{
N. Kano $(\bowtie) \cdot$ A. Takeshi $\cdot$ H. Kusanagi · Y. Watarai ·

M. Mike - S. Yamada - O. Mishima - S. Uwafuji .

M. Kitagawa - H. Watanabe - S. Kitahama ·

S. Matsuda $\cdot$ S. Endo

Department of Surgery, Kameda Medical Center,

929 Higashi-cho, Kamogawa, Chiba-ken 296-8602, Japan

e-mail: nkano@alpha.ocn.ne.jp

D. Gremillion

Department of Education, Kameda Medical Center,

929 Higashi-cho, Kamogawa, Chiba-ken 296-8602, Japan
}

cases managed by surgeons whose experience involved more than 13 cases of surgery [5]. Deziel et al. [6] reported that the incidences of biliary injury at the institutions with experience involving fewer than 100 cases of LC were significantly higher than those at institutions whose experience included more than 100 cases. Their report emphasized the importance of training for experienced and established surgeons starting to perform endoscopic surgery. In the recent literature, Hobbs et al. [7] reported that after the introduction of LC in 1991, the prevalence of all complications doubled by 1994 and then stabilized, whereas that of bile duct injury declined after 1994.

The age has changed since the introduction of LC, and the great concern is how to educate both young surgical residents starting their careers as surgeons and surgeons with experience in open surgery. Currently, the main concern is how to give a well-balanced education to young surgical residents in both open and laparoscopic surgery [8].

The rapid expansion of endoscopic surgery has led to concern about education for conventional open surgery. We conclude that there need be little concern about surgical education in this era of endoscopic surgery. By experiencing both open and endoscopic surgery, residents currently learn more meticulous anatomy than their senior surgeons learned in their younger days. During laparoscopic surgery, they can learn fine anatomy through magnified images on monitors. The anatomic relationship of the cystic duct and cystic artery seen behind the gallbladder neck can be visualized easily in laparoscopic surgery, a view not provided by open surgery. By experiencing both open and laparoscopic surgery, residents can learn more meticulous operative anatomy and technique, demonstrating a synergistic effect in surgical training (Fig. 1). 


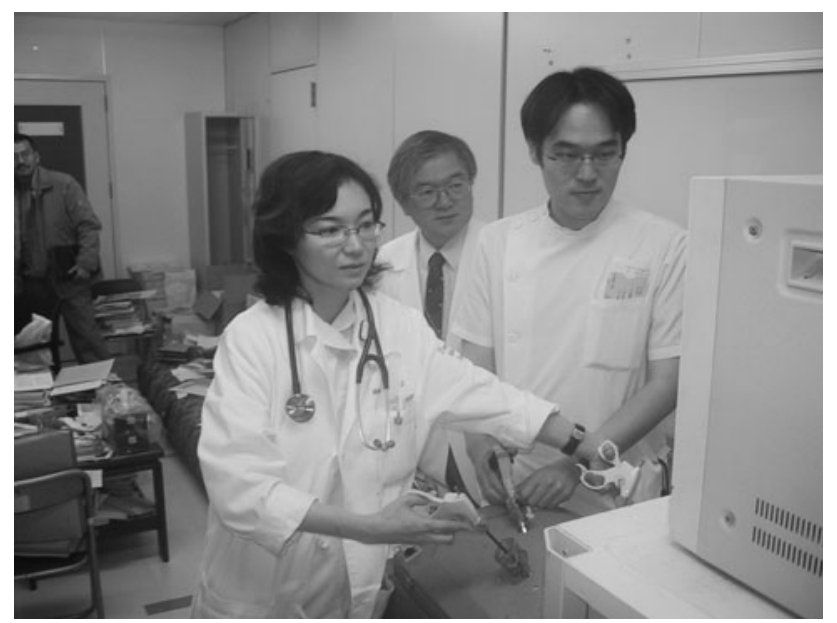

Fig. 1 Hands on training by residents themselves

\section{Training of Surgeons}

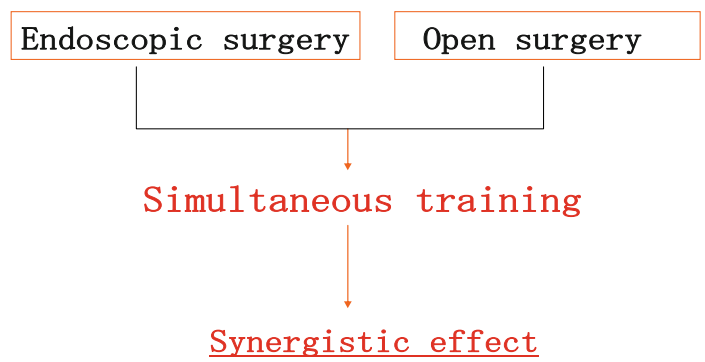

Fig. 2 Synergetic effect by simultaneous training

Surgical residents at our institution are given sufficient experience in both open conventional surgery and laparoscopic surgery. They are educated by senior surgeons with enough experience in open and endoscopic surgery. The synergistic effect of simultaneous training in open and endoscopic surgery is realized (Fig. 2).

Another policy in our surgical training is early exposure of trainees as primary surgeons. Even the first-year surgical residents can experience LC and open gastrectomy. However, this type of system appears to be very difficult in many other institutions in Japan. Although the education and training system for surgery often appears as a discussion topic at the surgical congresses in Japan, very few references are available on the synergistic effect of teaching both open and laparoscopic surgery in parallel in contemporary practice in Japan and elsewhere (Tables 1 , $2,3,4)$.

Some surgeons report that they have started requiring surgical residents to do surgeries as primary surgeons, but not until about the 10th year after graduation. Surgical residents progress more rapidly in the parallel open/ laparascopic model, and this is a strong recruiting incentive for programs that offer it.
Table 1 Guidelines for performing endoscopic surgery (JSES 2(I):7), proposed by Japan Society for Endoscopic Surgery, 29 August, 1992, 4 December 1996 (4th revision)

The training should be focused on

Techniques necessary for general open abdominal or chest surgery, preoperative management of patients, and management of predictable postoperative complications

A thorough understanding and management of the varied anatomies seen through the video monitor

Laparoscopic or thoracoscopic technique and a thorough understanding of its purposes.

Depth perception under two-dimensional video imaging

Tactile sensation of the organs through remote control

Eye-hand coordination through a magnified view

Technical know-how of specialized equipments

The Japan Society of Endoscopic Surgery recommends that privileges to perform endoscopic surgery should be granted only to individuals who meet the following criteria:

Is a qualified surgeon of one of the following societies:

Japanese Surgical Society

Japanese Society of Obstetrics and Gynecology

Japanese Urological Association

Japanese Orthopaedic Association

Has had at least 10 experiences of endoscopic surgery as an assistant under the supervision of an experienced surgeon

Has had at least 10 experiences endoscopic surgery as an operator under the supervision of an experienced surgeon

Has expertise in open surgery

Participates in the meetings or training courses accredited by Japan Society of Endoscopic Surgery

In addition, continuation of animal laboratory experience and training using simulators are strongly advocated for the acquisition of surgical skills.

Table 2 Criteria for evaluating endoscopic surgical skill at the Kameda Medical Center

Level 1: Has finished the fundamental training course recommended by the Japan Society for Endoscopic Surgery

Level 2: Has experienced 10 or more cases of endoscopic surgery as the second assistant or a laparoscopist

Level 3: Has experienced 10 or more cases of endoscopic surgery as the first assistant

Level 4: Has experienced 10 or more cases of endoscopic surgery as the operator

Level 5: Can manage difficult cases under the mentorship of senior surgeons

Level 6: Has finished the aforementioned training and can deal with more difficult operations using open and endoscopic surgery including unexpected occurrences during operations

Hands-on training under two-dimensional vision is indispensable for the training of endoscopic surgery. Therefore, the training room in the dry lab at our 
Table 3 Progress of surgical residents during 2 years of training (rated every 6 months in terms of levels)

\begin{tabular}{lllll}
\hline & A & B & C & D \\
\hline 0 months & 1 & 1 & 1 & 1 \\
6 months & 3 & 3 & 3 & 3 \\
12 months & 4 & 4 & 4 & 4 \\
18 months & 5 & 5 & 5 & 5 \\
24 months & 5 & 5 & 5 & 5 \\
\hline
\end{tabular}

Table 4 Three generations of surgeons currently classified by their educational background

1. Open surgery $\Rightarrow$ endoscopic surgery

2. Open surgery $\Leftrightarrow$ endoscopic surgery

3 . Open surgery $\Rightarrow$ open surgery

institution, available anytime to anybody, is working well for educating beginners. The effectiveness of training using bench models has been documented [9, 10]. Recently, more effective training using virtual reality simulators is increasingly reported [11-13]. Vlaovic and McDougall [12] reported that surgical simulation may provide an opportunity to enhance residency experience and training and to optimize the postgraduate acquisition of new skills and maintenance of competency. Surgical simulation will be an important adjunct to the traditional methods of surgical skills training, allowing surgeons to maintain their proficiency in the technically challenging aspects of minimally invasive surgery. We currently are using Lap MentorTW technology.

The surgeon pioneers who contributed to the development of endoscopic surgery in its early stage established their prestige in the field of open surgery. They introduced and learned endoscopic surgery after they had mastered conventional open surgery. In contrast, young surgeons currently learn open and endoscopic surgery in parallel, or they learn laparoscopic surgery first and then learn open surgery (e.g., cholecystectomy). They may learn in an order opposite that of the conventional teaching system. Still another group of surgeons adhere only to open surgery and show little interest in learning endoscopic surgery.

The surgical world currently consists of these three generations. It will be increasingly difficult for the third generation to survive in the 21st century. Funch-Jensen [14] reported that surgery is increasingly reoriented into laparoscopic procedures, and classic open surgery will presumably, with few exceptions, cease to exist in the future. We do not think open surgery will disappear and therefore believe that its skills must be maintained for the future.
Simultaneous training of conventional open surgery and endoscopic surgery provides a synergistic effect in the education of surgical residents. However, even with the rapid expansion of endoscopic surgery, education in open surgery will continue to be important in the training of young surgeons.

Disclosures Nobuyasu Kano, Akihiko Takeshi, Hiroshi Kusanagi, Yu Watarai, Makio Mike, Shigetoshi Yamada, Osamu Mishima, Seiko Uwafuji, Michiko Kitagawa, Hiroyuki Watanabe, Seiji Kitahama, Satoshi Matsuda, Satoshi Endo, and David Gremillion have no conflicts of interest or financial ties to disclose.

Open Access This article is distributed under the terms of the Creative Commons Attribution Noncommercial License which permits any noncommercial use, distribution, and reproduction in any medium, provided the original author(s) and source are credited.

\section{References}

1. Kano N, Yamakawa T (1992) Experience with laparoscopic cholecystectomy and its future outlook. Dig Endosc 4:179-185

2. Sackier J (1990) Training and education in laparoscopic surgery. In: Cuschieri A, Berci G (eds) Laparoscopic biliary surgery. Blackwell Scientific Publication, London, pp 1-8

3. Kimura T, Suzuki K (1994) Educational strategy in endoscopic surgery (in Japanese). Geka Surg 56:1509-1515

4. Scott TR, Zucker KA, Baily RW (1992) Laparoscopic cholecystectomy: a review of 12,397 patients. Surg Laparosc Endosc 2:191-198

5. Southern Surgeons Club (1991) A prospective analysis of 1,518 laparoscopic cholecystectomies. N Eng J Med 324:1073-1078

6. Deziel DJ, Millikan KW, Economou SG, Doolas A, Ko ST, Airan MC (1993) Complications of laparoscopic cholecystectomy: a national survey of 4,292 hospitals and an analysis of 77,604 cases. Am J Surg 165:9-14

7. Hobbs MS, Mai Q, Kunuiman MW, Fletcher DR, Ridout SC (2006) Surgeons' experience and trends in intraoperative complications in laparoscopic cholecystectomy. Br J Surg 3:844-853

8. Kano N (2001) An idea on training of surgeons in the era of endoscopic surgery (in Japanese). J Jpn Coll Surg 6:188-191

9. Scott DJ, Bergen PC, Rege RV, Laycock R, Tesfy ST, Valentine RJ, Euhus DM, Jeyarajah DR, Thompson WM, Jones DB (2000) Laparoscopic training on bench models: better and more cost effective than operating room experience? J Am Coll Surg 1: 272-283

10. Nguyen NT, Mayer KL, Bold RJ, Larson M, Foster S, Ho HS, Wolfe BM (2000) Laparoscopic suturing evaluation among surgical residents. J Surg Res 3:133-136

11. Schijven MP, Jkimowicz JJ (2003) Introducing the Sitact LS500 laparoscopy simulator: toward a revolution in surgical education. Surg Technol Int 1:32-36

12. Vlaovic PD, McDougall EM (2006) New age teaching: beyond didactics. Sci World J 6:2370-2380

13. Roberts KE, Bell RL, Duffy AJ (2006) Evolution of surgical skills training. World J Gastroenterol 12:3219-3224

14. Funch-Jensen P (2008) Surgical training. Dan Med Bull 55:128 